\title{
Practical synthesis of indoles and benzofurans in water using a heterogeneous bimetallic catalyst
}

\author{
Cybille Rossy ${ }^{1,2}$, Eric Fouquet ${ }^{1}$ and François-Xavier Felpin ${ }^{* 2}$
}

\section{Letter}

\section{Address:}

${ }^{1}$ Université de Bordeaux, UMR CNRS 5255, ISM, 351 cours de la Libération, 33405 Talence Cedex, France and ${ }^{2}$ Université de Nantes, UFR Sciences et Techniques, UMR CNRS 6230, CEISAM, 2 rue de la Houssinière, BP 92208, 44322 Nantes Cedex 3, France

Email:

François-Xavier Felpin* - fx.felpin@univ-nantes.fr

* Corresponding author

Keywords:

benzofuran; bimetallic catalyst; heterogeneous catalysis; indole; water
Beilstein J. Org. Chem. 2013, 9, 1426-1431. doi:10.3762/bjoc. 9.160

Received: 23 May 2013

Accepted: 25 June 2013

Published: 16 July 2013

Associate Editor: B. Stoltz

(C) 2013 Rossy et al; licensee Beilstein-Institut. License and terms: see end of document.

\begin{abstract}
This paper describes the preparation of indoles, azaindoles and benzofurans in pure water by using a new heterogeneous $\mathrm{Pd}-\mathrm{Cu} / \mathrm{C}$ catalyst through a cascade Sonogashira alkynylation-cyclization sequence. Details of the optimization studies and the substrate scope are discussed. This procedure allows the preparation of heterocycles with good yields and is tolerant to a wide variety of functional groups.
\end{abstract}

\section{Introduction}

Heterocycles are ubiquitous building blocks in natural products, bioactive compounds and materials. Amongst the variety of heterocycles, indoles and benzofurans have emerged as privileged structures, especially in medicinal chemistry [1]. This great interest stimulated organic chemists to design efficient and diverse synthetic accesses, abundantly reviewed in the past few years [2-7]. A detailed survey of the recent literature revealed that both indoles and benzofurans can be attained by a cascade Sonogashira alkynylation-cyclization sequence (Scheme 1).

Many efficient catalytic systems have been reported since the pioneering studies of Yamanaka [8] and this approach is now a classic for the synthesis of indole- and benzofuran-containing natural products [9-13] and biologically relevant agents [14-18].

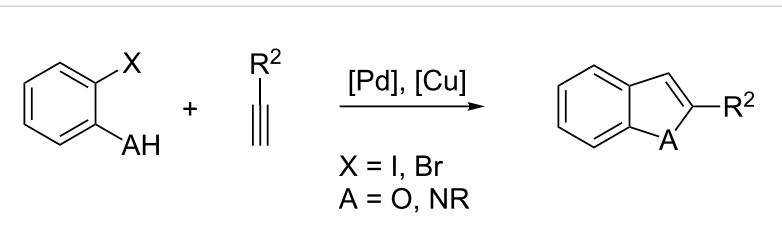

Scheme 1: Sonogashira alkynylation-cyclization sequence for indole and benzofuran syntheses.

The traditional procedure requires a homogeneous source of palladium and copper in a polar solvent (usually DMF) with an organic base such as $\mathrm{Et}_{3} \mathrm{~N}$. The role of copper is twofold since it acts not only as a cocatalyst for the alkynylation reaction but also as a Lewis acid for the cyclization step. Procedures 
involving heterogeneous catalysts have been much less explored and essentially limited to the use of heterogeneous Pd catalysts in the presence of $\mathrm{CuI}$ [19-21]. Alternatively, copperfree heterogeneous catalysis has been proposed thanks to the Lewis acid properties of zeolite $\left[\left(\mathrm{NH}_{4}\right) \mathrm{Y}\right]$ used as support [2224]. A challenging approach consisting of a heterobimetallic catalysis has been occasionally envisaged. This area was pioneered by the group of Dkajovitch, which developed new $\mathrm{Pd}-\mathrm{Cu} / \mathrm{SiO}_{2}$ and $\mathrm{Pd}-\mathrm{Cu} / \mathrm{NaY}$ catalysts for the preparation of the 2-phenylindole in aqueous DMF [25]. More recently, $\mathrm{Cu}(\mathrm{I})-\mathrm{Pd}(\mathrm{II})$-containing polymer [26] and palladium-copper on magnetite [27] complexes have been introduced as efficient catalysts for preparing indoles and benzofurans in NMP and toluene, respectively. Considering that a catalyst working in water would be appealing [28], we hypothesized that activated charcoal could be a support of choice for palladium and copper due to its robustness and inertness [29-32]. In this paper we wish to describe the use of a readily available heterobimetallic $\mathrm{Pd}-\mathrm{Cu} / \mathrm{C}$ catalyst for cascade Sonogashira alkynylation-cyclization sequences in pure water leading to indoles, azaindoles and benzofurans.

\section{Results and Discussion}

We recently reported a simple and efficient procedure for preparing a very active, activated-charcoal-supported palladium catalyst for hydrogenation and debenzylation [33]. This homemade $\mathrm{Pd} / \mathrm{C}$ catalyst was prepared by impregnation of activated charcoal by the reduction of $\mathrm{Pd}(\mathrm{OAc})_{2}$ in $\mathrm{MeOH}$ under an atmosphere of $\mathrm{H}_{2}(1 \mathrm{~atm})$. With these previous results in mind, we reasoned that the concomitant impregnation of charcoal with palladium and copper could lead to a heterogeneous bimetallic catalyst, hopefully active for cascade Sonogashira alkynylation-cyclization sequences. Following this aim, we were pleased to find that the stirring of a mixture of $\mathrm{Pd}(\mathrm{OAc})_{2}$, $\mathrm{Cu}(\mathrm{OAc})_{2}$ and activated charcoal in $\mathrm{MeOH}$ under an atmosphere of $\mathrm{H}_{2}(1 \mathrm{~atm})$ furnished a heterogeneous bimetallic catalyst. The content of $\mathrm{Pd}(\sim 5 \mathrm{wt} \%)$ and $\mathrm{Cu}(\sim 3.6 \mathrm{wt} \%)$ was determined by ICPMS analysis.

With the aim of developing a heterogeneous bimetallic catalysis in water, we took inspiration from the work of Pal et al [34], who reported the preparation of indoles in a $\mathrm{Pd} / \mathrm{C}$-catalysed reaction in water with $\mathrm{CuI}$ as co-catalyst, $\mathrm{Ph}_{3} \mathrm{P}$ as ligand and 2-aminoethanol as base. To our great pleasure, the application of these conditions with our $\mathrm{Pd}-\mathrm{Cu} / \mathrm{C}$ catalyst, for the coupling of iodoaniline 1 with phenylacetylene (2) provided the expected indole 3 with an excellent $90 \%$ yield (Table 1 , entry 1). Interestingly, Pd-free (Table 1, entry 2 ) or Cu-free (Table 1 , entry 3 ) conditions were detrimental for the reaction efficiency, suggesting the cooperative role of $\mathrm{Pd}$ and $\mathrm{Cu}$. The metal loading was also evaluated and the best compromise was found at $2 \mathrm{~mol} \mathrm{\%} \mathrm{Pd} \mathrm{(Table} \mathrm{1,} \mathrm{entry} \mathrm{4).} \mathrm{It} \mathrm{is} \mathrm{worth} \mathrm{noting} \mathrm{that} \mathrm{phenyl-}$ acetylene (2) was secured from dimerization by $\mathrm{O}_{2}$ exclusion through a gentle bubbling of argon. Interestingly, the use of aqueous $\mathrm{iPrOH}$ instead of pure water for enhancing the solubility of the organics slightly decreased the efficiency of our catalytic system highlighting the role of water in solvating the substrates.

Table 1: Optimization of the catalyst loading. ${ }^{a}$

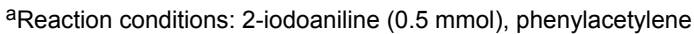
(1 $\mathrm{mmol})$, ethanolamine $(1.5 \mathrm{mmol}), \mathrm{Ph}_{3} \mathrm{P}(5 \mathrm{~mol} \%)$ and catalyst (see table) were stirred in water $(3 \mathrm{~mL})$ at $80^{\circ} \mathrm{C}$ under Ar for $20 \mathrm{~h}$. blsolated yield. ${ }^{\mathrm{C}}$ This catalyst was made following the procedure described for $\mathrm{Pd}-\mathrm{Cu} / \mathrm{C}$.

We then evaluated the influence of the nitrogen protecting group for the cascade Sonogashira coupling-cyclization sequence on two model reactions (Scheme 2). We observed that the coupling of phenyl acetylene (2) with variously $\mathrm{N}$-protected-2-iodoanilines gave contrasted results. Indeed, excellent yields of the corresponding indoles were obtained with anilines bearing mesyl, tosyl or Boc protecting groups (compounds 3-5), while only an uncyclized product was obtained with acetate (compound 7). The free indole was obtained when a trifluoroacetate function was used as protecting group, albeit in modest yield. The loss of the trifluoroacetate group likely occurred during the workup process. It should be noted that unprotected aniline exclusively led to the uncyclized Sonogashira adduct. Surprisingly a much pronounced $\mathrm{N}$-substituent effect was observed with hexyne as coupling partner, where the tosyl protecting group gave the best result. These results strongly suggest that both electronic and steric factors participate in the cyclization step.

With these optimized conditions in hand, we next focused on the reaction scope for which we prepared a series of 2-iodoanilines (Scheme 3) and 2-amino-3-iodopyridines (Scheme 4). 


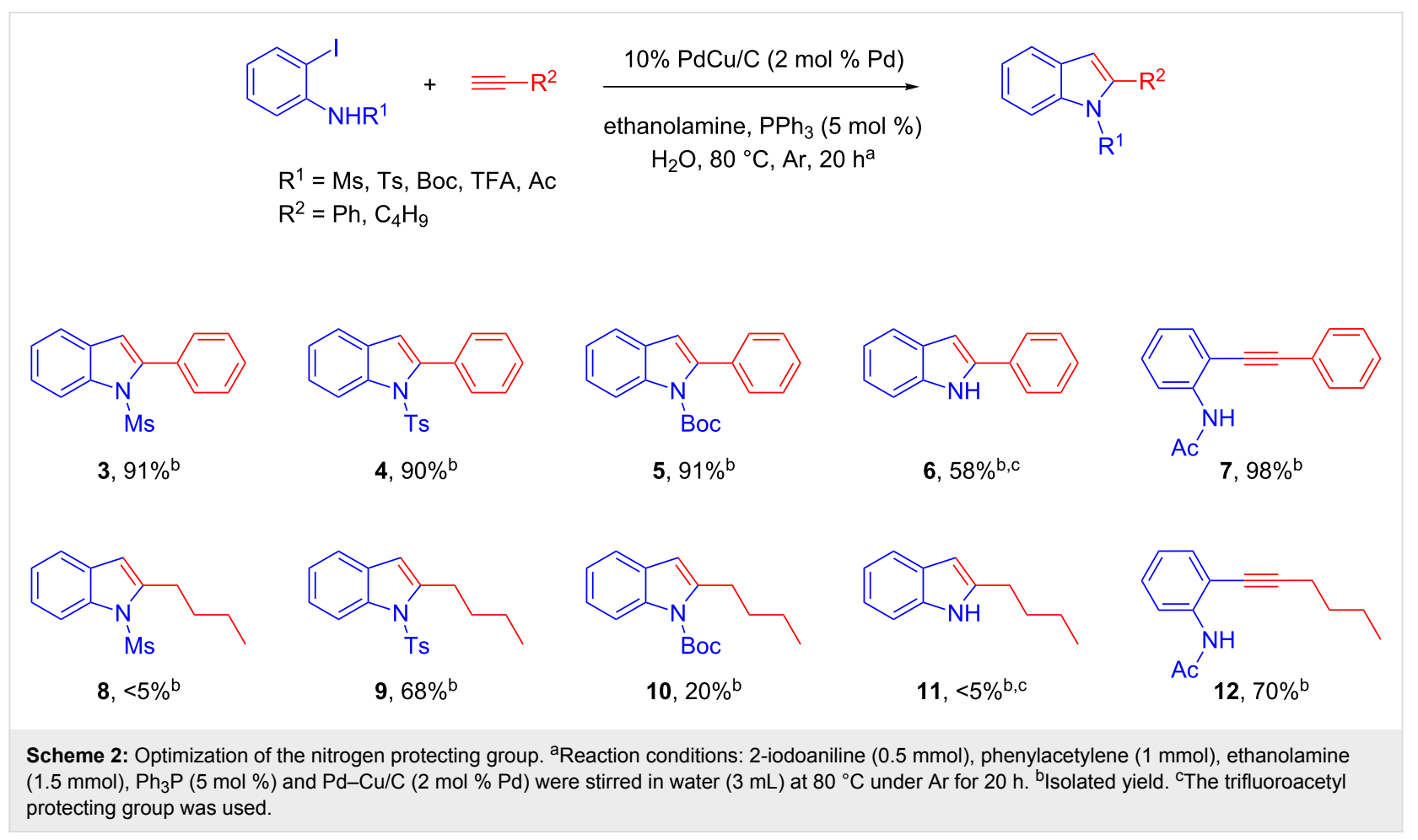

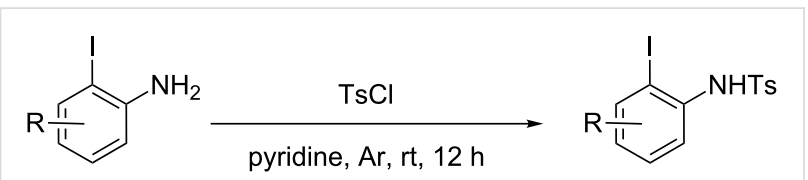<smiles>N#Cc1ccc(N[15SH])c(I)c1</smiles>

$13,75 \%$
$15,10 \%$

$16,25 \%$

Scheme 3: Preparation of N-protected 2-iodoanilines.
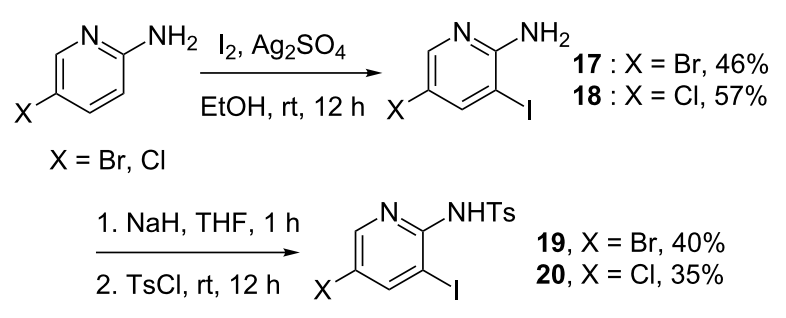

Scheme 4: Preparation of N-protected 3-iodo-2-aminopyridines.

2-Iodoanilines 13-16 were prepared following a standard procedure [35] although only $\mathbf{1 3}$ was known at the time of our studies. The preparation of 3-iodo-2-aminopyridines proved to be much more complicated. Indeed, the poor nucleophilicity of amino pyridine $\mathbf{1 7}$ and $\mathbf{1 8}$ precluded any tosylation under standard conditions. After extensive experimentations we found that

the activation of the amino group with a strong base such as $\mathrm{NaH}$ allowed the preparation of the expected compounds 19 and 20 in acceptable yields.

The Sonogashira alkynylation-cyclization sequence was successfully applied to a variety of alkynes and iodo-anilines (Scheme 5). As a general comment, aromatic alkynes consistently furnished a high yield of the corresponding indoles whatever the nature of the electrophile (compounds 4, 21, 22). For instance, the reaction was remarkably selective toward the iodine atom, leaving other halogens $(\mathrm{Cl}$ and $\mathrm{Br})$ unaffected. Moreover, 3-iodo-2-aminopyridines 19 and 20 were remarkably reactive, giving the corresponding azaindoles 23 and $\mathbf{2 4}$ with excellent yields. On the other hand, aliphatic alkynes gave lower but still synthetically useful yields, even in the presence of halogens and free alcohols. Interestingly, indole 9 was obtained with an improved yield of $89 \%$ versus $68 \%$ when the corresponding 2-bromoaniline was used instead of the 2 -iodoaniline 13. However, this trend was not observed with aryl acetylenes suggesting a strong halide effect and a sensitivity of the $\mathrm{Pd}-\mathrm{X}$ bond under our reaction conditions. Indeed, the coupling of aryl acetylenes with bromo-anilines and bromophenols showed lower conversion compared to the iodocongeners. We further evaluated the potential of our $\mathrm{Pd}-\mathrm{Cu} / \mathrm{C}$ catalyst for the alkynylation-cyclization of 2-iodophenols in view of preparing benzofurans. As already observed with the synthesis of indoles, aliphatic alkynes gave slightly lower yields than aryl acetylenes. A remarkable tolerance toward reactive 


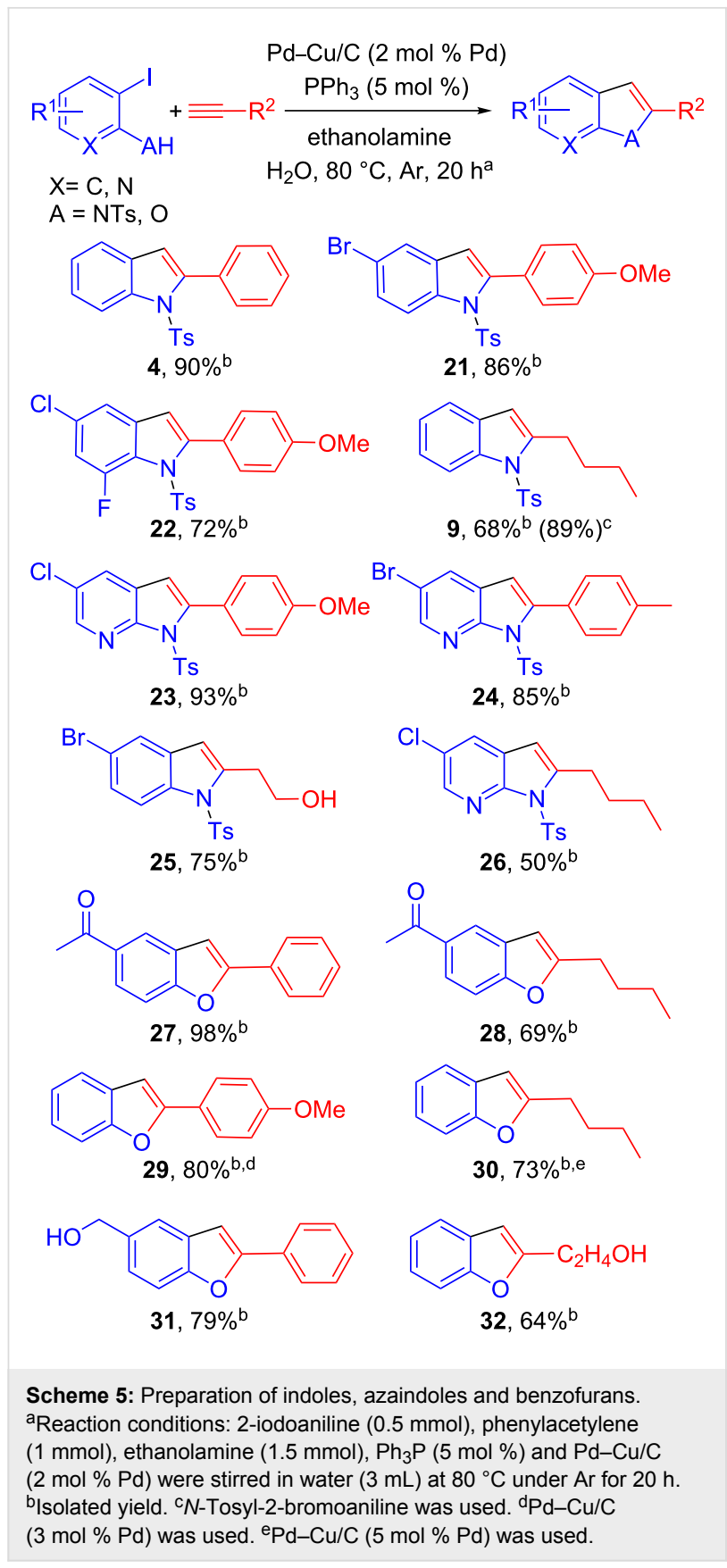

functions such as ketones and alcohols, including benzylic ones, was observed with this catalytic system, highlighting the versatility of our heterogeneous bimetallic catalytic system. This methodology using a homemade $\mathrm{Pd}-\mathrm{Cu} / \mathrm{C}$ catalyst is one of the rare examples of a multitask heterogeneous bimetallic catalysis for tandem or cascade reactions $[36,37]$.

Finally, the recyclability of our homemade $\mathrm{Pd}-\mathrm{Cu} / \mathrm{C}$ catalyst was evaluated for the preparation of indole 4. Unfortunately, we found that the yield dramatically decreases to $60 \%$ (compared to $90 \%$ with the fresh catalyst) after the second run and the cata- lyst was inactive after the third run. ICPMS analyses of the filtered solution after the three runs showed a marginal leaching of $\operatorname{Pd}(<0.5 \%$ based on the amount initially introduced $)$ while a different trend was observed for copper. Indeed, $15 \%$ of the copper (based on the initial amount introduced) was detected in the filtered solution after the first run, while virtually no leaching occurred in the subsequent runs. These results suggested that the diminished activity cannot be attributed to the copper leaching. A similar deactivation was observed by Djakovitch and co-workers with their $\mathrm{Pd}-\mathrm{Cu} / \mathrm{NaY}$ catalyst that likely occurred during the separation from the reaction media [23]. We believe that a similar behaviour can explain the catalyst deactivation observed in our studies. The use of flow technology might address this issue as stated by Djakovitch et al., and we are currently investigating this promising alternative.

\section{Conclusion}

In summary we have described a new water-compatible heterogeneous $\mathrm{Pd}-\mathrm{Cu} / \mathrm{C}$ catalyst for cascade Sonogashira alkynylation-cyclization sequences leading to indoles, azaindoles and benzofurans. The procedure allows the preparation of useful heterocycles under water-only conditions and with inexpensive ligand and base. Current studies focusing on the preparation of more robust and recyclable heterogeneous bimetallic catalysts for batch and flow processes are underway in our laboratory.

\section{Experimental}

Catalyst preparation: The $\mathrm{Pd}-\mathrm{Cu} / \mathrm{C}$ was prepared by the following procedure. $\mathrm{Pd}(\mathrm{OAc})_{2}(119 \mathrm{mg}, 0.5 \mathrm{mmol}), \mathrm{Cu}(\mathrm{OAc})_{2}$ $(170 \mathrm{mg}, 0.9 \mathrm{mmol})$ and charcoal $(1 \mathrm{~g})$ were dispersed in $\mathrm{MeOH}(100 \mathrm{~mL})$. Then, hydrogen gas was bubbled through the solution for 5 minutes to remove oxygen. The resulting mixture was stirred for $12 \mathrm{~h}$ at $25{ }^{\circ} \mathrm{C}$ under $\mathrm{H}_{2}$ ( $1 \mathrm{~atm}$, balloon). The catalyst was filtered under a Millipore membrane (filters nylon $0.45 \mu \mathrm{m}, 47 \mathrm{~mm}$ ), washed with $\mathrm{MeOH}$ and dried under vacuum. ICP analyses were performed on the filtrate to verify the final Pd-metal loading on carbon to be $5 \mathrm{wt} \%$ and $\mathrm{Cu}$-metal loading on carbon to be $3.6 \mathrm{wt} \%$.

General procedure for the preparation heterocycles: In a sealed tube, aryl iodide ( $0.5 \mathrm{mmol}, 1.0$ equiv), $\mathrm{PPh}_{3}(5 \mathrm{~mol} \%)$ and catalyst $\mathrm{Pd}-\mathrm{Cu} / \mathrm{C}(2 \mathrm{~mol} \%)$ were suspended in $\mathrm{H}_{2} \mathrm{O}(3 \mathrm{~mL})$ previously degassed. Then, acetylene derivative $(1.0 \mathrm{mmol}$, 2.0 equiv) and ethanolamine ( $1.5 \mathrm{mmol}, 3.0$ equiv) were added. The resulting mixture was stirred $20 \mathrm{~h}$ at $80{ }^{\circ} \mathrm{C}$ under argon atmosphere. After cooling to room temperature, DCM (10 mL) and $\mathrm{H}_{2} \mathrm{O}(10 \mathrm{~mL})$ were added and the mixture was filtered over a pad of Celite ${ }^{\circledR}$. The aqueous layer was extracted twice with DCM $(2 \times 10 \mathrm{~mL})$. The collected organic extracts were washed by brine $(20 \mathrm{~mL})$, dried over $\mathrm{MgSO}_{4}$, filtered and concentrated under reduced pressure. 


\section{Supporting Information}

\section{Supporting Information File 1}

Experimental details and characterization of compounds synthesized.

[http://www.beilstein-journals.org/bjoc/content/ supplementary/1860-5397-9-160-S1.pdf]

\section{Acknowledgements}

We gratefully acknowledge the "Université de Bordeaux", the "Université de Nantes", the "Centre National de la Recherche Scientifique (CNRS)", and the "Agence Nationale de la Recherche" (ANR JCJC 7141) for the financial support of this project. We thank O. Brugier and C. Douchet (Université Montpellier) for ICPMS analyses. F.-X. Felpin is a member of the "Institut Universitaire de France (IUF)".

\section{References}

1. Lounasmaa, M.; Tolvanen, A. Nat. Prod. Rep. 2000, 17, 175-191. doi:10.1039/a809402k

2. Humphrey, G. R.; Kuethe, J. T. Chem. Rev. 2006, 106, 2875-2911. doi: $10.1021 /$ cr0505270

3. Taber, D. F.; Tirunahari, P. K. Tetrahedron 2011, 67, 7195-7210. doi:10.1016/j.tet.2011.06.040

4. Cacchi, S.; Fabrizi, G. Chem. Rev. 2011, 111, PR215-PR283. doi:10.1021/cr100403z

5. Cacchi, S.; Fabrizi, G.; Goggiamani, A. Org. Biomol. Chem. 2011, 9, 641-652. doi:10.1039/c0ob00501k

6. Vicente, R. Org. Biomol. Chem. 2011, 9, 6469-6480. doi:10.1039/c1ob05750b

7. Platon, M.; Amardeil, R.; Djakovitch, L.; Hierso, J.-C. Chem. Soc. Rev. 2012, 41, 3929-3968. doi:10.1039/c2cs15350e

8. Sakamoto, T.; Kondo, Y.; Iwashita, S.; Nagano, T.; Yamanaka, H. Chem. Pharm. Bull. 1988, 36, 1305-1308. doi:10.1248/cpb.36.1305

9. Hiroya, K.; Matsumoto, S.; Sakamoto, T. Org. Lett. 2004, 6, 2953-2956. doi:10.1021/ol0489548

10. Wang, C.; Sperry, J. Org. Lett. 2011, 13, 6444-6447. doi:10.1021/ol2027398

11. Harada, M.; Asaba, K. N.; Iwai, M.; Kogure, N.; Kitajima, M.; Takayama, H. Org. Lett. 2012, 14, 5800-5803. doi:10.1021/ol3027945

12. Jana, G. K.; Sinha, S. Tetrahedron 2012, 68, 7155-7165. doi:10.1016/j.tet.2012.06.027

13. Wang, C.; Sperry, J. Synlett 2012, 23, 1824-1828. doi:10.1055/s-0031-1290693

14. Harper, S.; Pacini, B.; Avolio, S.; Di Filippo, M.; Migliaccio, G.; Laufer, R.; De Francesco, R.; Rowley, M.; Narjes, F. J. Med. Chem. 2005, 48, 1314-1317. doi:10.1021/jm049122i

15. Dorow, R. L.; Herrinton, P. M.; Hohler, R. A.; Maloney, M. T.; Mauragis, M. A.; McGhee, W. E.; Moeslein, J. A.; Strohbach, J. W.; Veley, M. F. Org. Process Res. Dev. 2006, 10, 493-499. doi:10.1021/op050251y

16. Lanter, J. C.; Fiordeliso, J. J.; Allan, G. F.; Musto, A.; Hahn, D. W.; Sui, Z. Bioorg. Med. Chem. Lett. 2006, 16, 5646-5649. doi:10.1016/j.bmcl.2006.08.036
17. Watanabe, H.; Ono, M.; Haratake, M.; Kobashi, N.; Saji, H.; Nakayama, M. Bioorg. Med. Chem. 2010, 18, 4740-4746. doi:10.1016/j.bmc.2010.05.013

18. Capes, A.; Patterson, S.; Wyllie, S.; Hallyburton, I.; Collie, I. T.; McCarroll, A. J.; Stevens, M. F. G.; Frearson, J. A.; Wyatt, P. G.; Fairlamb, A. H.; Gilbert, I. H. Bioorg. Med. Chem. 2012, 20 , 1607-1615. doi:10.1016/j.bmc.2011.12.018

19. Gruber, M.; Chouzier, S.; Koehler, K.; Djakovitch, L. Appl. Catal., A 2004, 265, 161-169. doi:10.1016/j.apcata.2004.01.012

20. Layek, M.; Gajare, V.; Kalita, D.; Islam, A.; Mukkanti, K.; Pal, M. Tetrahedron Lett. 2009, 50, 3867-3871. doi:10.1016/j.tetlet.2009.04.048

21. Prasad, B.; Adepu, R.; Sandra, S.; Rambabu, D.; Krishna, G. R.; Reddy, C. M.; Deora, G. S.; Misra, P.; Pal, M. Chem. Commun. 2012, 48, 10434-10436. doi:10.1039/c2cc35757g

22. Hong, K. B.; Lee, C. W.; Yum, E. K. Tetrahedron Lett. 2004, 45, 693-697. doi:10.1016/j.tetlet.2003.11.075

23. Djakovitch, L.; Rollet, P. Adv. Synth. Catal. 2004, 346, 1782-1792. doi:10.1002/adsc.200404141

24. Djakovitch, L.; Dufaud, V.; Zaidi, R. Adv. Synth. Catal. 2006, 348, 715-724. doi:10.1002/adsc.200505283

25. Chouzier, S.; Gruber, M.; Djakovitch, L. J. Mol. Catal. A: Chem. 2004, 212, 43-52. doi:10.1016/j.molcata.2003.11.027

26. Magdesieva, T. V.; Nikitin, O. M.; Yakimansky, A. V.; Goikhman, M. Ya.; Podeshvo, I. V. Electrochim. Acta 2011, 56, 3666-3672. doi:10.1016/j.electacta.2010.10.075

27. Cano, R.; Yus, M.; Ramón, D. J. Tetrahedron 2012, 68, 1393-1400. doi:10.1016/j.tet.2011.12.042

28. Lamblin, M.; Nassar-Hardy, L.; Hierso, J.-C.; Fouquet, E.; Felpin, F.-X. Adv. Synth. Catal. 2010, 352, 33-79. doi:10.1002/adsc.200900765

29. Felpin, F.-X.; Ayad, T.; Mitra, S. Eur. J. Org. Chem. 2006, 2006, 2679-2690. doi:10.1002/ejoc.200501004

30. Seki, M. Synthesis 2006, 2975-2992. doi:10.1055/s-2006-950197

31. Yin, L.; Liebscher, J. Chem. Rev. 2007, 107, 133-173. doi:10.1021/cr0505674

32. Pal, M. Synlett 2009, 2896-2912. doi:10.1055/s-0029-1218021

33. Felpin, F.-X.; Fouquet, E. Chem.-Eur. J. 2010, 16, 12440-12445. doi:10.1002/chem.201001377

34. Pal, M.; Subramanian, V.; Batchu, V. R.; Dager, I. Synlett 2004, 1965-1969. doi:10.1055/s-2004-830861

35. Mailyan, A. K.; Geraskin, I. M.; Nemykin, V. N.; Zhdankin, V. V. J. Org. Chem. 2009, 74, 8444-8447. doi:10.1021/jo901638f

36. Felpin, F.-X.; Fouquet, E. ChemSusChem 2008, 1, 718-724. doi:10.1002/cssc.200800110

37. Lipshutz, B. H.; Nihan, D. M.; Vinogradova, E.; Taft, B. R.; Bošković, Z. V. Org. Lett. 2008, 10, 4279-4282. doi:10.1021/ol801676u 


\section{License and Terms}

This is an Open Access article under the terms of the Creative Commons Attribution License

(http://creativecommons.org/licenses/by/2.0), which permits unrestricted use, distribution, and reproduction in any medium, provided the original work is properly cited.

The license is subject to the Beilstein Journal of Organic Chemistry terms and conditions:

(http://www.beilstein-journals.org/bjoc)

The definitive version of this article is the electronic one which can be found at:

doi:10.3762/bjoc. 9.160 